\section{Maintenance of Certification for Family Physicians (MC-FP)}

The new Maintenance of Certification for Family Physicians (MC-FP) has been in place since the beginning of 2004. During this time, we have engaged in a number of conversations with our diplomates via telephone, by e-mail, and in person to assist them with the process. These conversations have provided valuable feedback, which has allowed us to improve the MC-FP process. We have also discovered that there are some misperceptions about the process and its requirements. To continue to effectively communicate with our Diplomates, the Board felt it would be helpful to provide a current overview of the MC-FP and its components. Many of the changes that Diplomates have observed in this new certification process have been made as a direct result from feedback regarding the former certification process. New video and graphic technology and Internet/computer delivery channels have enabled us to answer those suggestions.

In Table 1, you will find a requirement comparison of the former certification requirements with today's MC-FP process. Following are more indepth explanations of each requirement.

\section{Rationale for Changing the 30-Year Old Certification/Recertification Process to the new MC-FP}

A number of reports issued in the late 1990s raised concerns about the health care system in the United States and cited a need for change to improve the delivery of health care to Americans. In response to these concerns, the American Board of Medical Specialties (ABMS) adopted a requirement that each of its 24 member boards develop specific mechanisms for implementing a Maintenance of Certification (MOC) process. The ABFM named their version MC-FP. The ABMS required that all boards submit a plan for instituting the first three parts of this process by July 2003, with the expectation that all boards would begin their MOC process shortly thereafter.

The rationale for the MOC process is that medical knowledge is changing more rapidly, and for patients to receive the benefits of these new developments, physicians should continuously update their knowledge and skills. The ABMS felt that one way to encourage continuous learning would be for specialty boards to assess their Diplomates more frequently than in the past. Furthermore, the ABMS felt that some of this assessment should focus on application of knowledge and on the patient/physician interface.

\section{The ABFM Strategy for Maintenance of Certification}

When the ABFM Board of Directors began planning to implement these requirements, they were very cognizant of the need to avoid imposing unnecessarily burdensome requirements on our diplomates. Many of our Directors are in private practice, and they understand the many pressures on the practicing physician.

To ease the transition to this new process, the entry of current diplomates into the MC-FP process will be staggered over 7 years. A new group will start the process each year, beginning the year after they recertify. Diplomates who recertified in 2003 entered MC-FP January 1, 2004, along with those who were certified for the first time in 2003. Those who are certified or recertified in 2004 will enter the process in 2005. This will continue until all Diplomates are participating beginning January $1,2010$.

\section{ABFM MC-FP Requirements Maintain a Valid and Unrestricted License (UNCHANGED)}

Most of the components necessary for the ABFM to meet the MOC requirement were already in place in some form. The first requirement that has been in place from the beginning for family physicians is proof of professional standing. The ABFM has always required a full, unrestricted license to maintain certification and this satisfied the ABMS requirement.

\section{Life-Long Learning (UNCHANGED)}

300 Hours of continuing medical education (CME) are still required; however, the ABMS requires a process to ensure that our diplomates' knowledge and skills are updated on a more ongoing basis than we have done with our examination in the past. To accomplish this, we are developing assessment tools that incorporate active learning, feedback, and application and are available on the Internet. Six of 
Maintenance of Certification for Family

Physicians (MC-FP) Requirements

I. UNCHANGED

II. Life-long Learning

a. (UNCHANGED) 300 hours CME required. ABFP web site assists in identifying sources to satisfy these requirements.

b. (NEw) Self-Assessment Module (SAM). Taken by computer. One completed SAM per year required (total of 6 per 7-year cycle). Up to 15 hours of approved CME credit per SAM.

III. Cognitive Exam

a. Paper and pencil test

b. Administered at a limited number of sites and dates.

IV. Computer Office Record Review (CORR)

a. Once per 7-year cycle

these self-assessment modules, or SAMs, must be completed during the 7-year MC-FP cycle, and the requirements have been designed to encourage Diplomates to complete 1 SAM per year, rather than several near the end of the MC-FP cycle; the first two SAMs have been approved for up to 15 hours of CME by the AAFP.

\section{Cognitive Expertise (formerly Cognitive Examination) (BASICALLY UNCHANGED)}

The ABMS specified that the physicians complete an objective assessment of knowledge in their field on a periodic basis, and the ABFM has required this of its diplomates from the beginning. Family physicians have been required to pass a written examination every 7 years to maintain their certification. Today, this examination is taken on computerwith the new technology available, we are able to provide more examination dates (11) and more test centers (202) than we could have with the paperand-pencil test.

\section{Evaluation of Performance in Practice Module [formerly Computerized Office Record Review (CORR)] (BASICALLY UNCHANGED)}

The final requirement is a demonstration of performance in practice. In some ways, this is similar to the Computerized Office Record Review that has been required for recertification by the ABFM for more than 20 years. There will be some changes to this process, and we believe that our diplomates will find it more useful and more applicable to practice. This will be required once every 7 years, and the first modules will be available in January of 2005. Physicians who are not responsible for providing continuity of care to patients will fulfill this requirement by completing an alternative activity that the ABFP will develop for this purpose. This group includes those in administrative positions, physicians working in emergency departments or urgent care centers, and others.

\section{Self-Assessment Modules-a Further Explanation}

The current SAMs and those under development by the ABFM correspond to the 20 priority areas identified by the Institute of Medicine in its report Priority Areas for National Health Action. Transforming Health Care Quality. In January 2004, we launched a SAM on hypertension and another on diabetes mellitus. In January 2005, 2 additional SAMs, one on asthma and one on coronary artery disease, became available. We will continue to add at least 2 categories per year and, in cooperation with other specialty boards, modules will be developed for topics related to sports medicine, geriatric medicine, and adolescent medicine.

These materials are similar in many ways to the CME requirement that has been in place in the past; in fact, the AAFP has approved up to 15 hours of prescribed CME credit for each of the two SAMs currently available. One difference is that the materials are available over the Internet, which pro- 
vides the convenience of completing the assessment anytime and anywhere there is an Internet connection available, with the advantage of allowing the diplomate to stop and return to the program at any time. A second difference is that the assessment is designed with a goal of demonstrating information mastery of the subject. The SAMs have two parts, and both must be completed to satisfy the requirement.

\section{Part I-Knowledge Assessment}

The first part of the SAM, the knowledge assessment portion, consists of 60 objective questions divided into several competencies. The diplomate must demonstrate mastery by correctly answering $80 \%$ of the questions in each competency. Multiple retakes are allowed with no penalty or additional fees, and references are provided online whenever feasible. Diplomates can also consult any resources they like during the assessment, including textbooks, journals, and even colleagues.

\section{Part II-Patient Simulation}

Once the in-depth learning and assessment activity is successfully completed (part I), the diplomate moves on to the patient simulation components (part II), where the knowledge is put into practice. The patient simulation component consists of a clinical presentation that is representative of the disease state. The patient's condition evolves as the simulation progresses, and the physician must respond to the changes. The simulation continues until either the patient's condition is stable for 3 successive office visits or 2 years of simulated time has elapsed, whichever comes first.
Improved Communications to Assist Our Diplomates Tutorial and Practice Examination

To help each diplomate become familiar with the new technology and delivery channels, we have created an online tutorial and practice examination. Please go to http://www.TheABFM.org and click on the Tutorial button. We are confident that this will demonstrate the added value that this new computer technology will provide to our diplomates. If you have questions, we encourage you to call or email us.

\section{Help Desk}

Our help desk provides immediate access to a live operator at 1-877-223-7437 and is staffed from 8:30 Aм to 9:00 Pм Eastern Standard Time, Monday through Friday, and 9:00 AM to 5:00 PM on Saturdays. Questions can also be asked and answered by email through our web site at http:// www.TheABFM.org.

\section{ABFP Changes Its Name to the American Board of Family Medicine (ABFM)}

Based on recommendations made by the Future of Family Medicine Project, the American Board of Family Practice has changed its name to the American Board of Family Medicine and its web site address to http://www.TheABFM.org. The name and web site address changes became official January 1, 2005. Certificates issued by the American Board of Family Practice before January 1, 2005, remain valid through their stated expiration date. 